\title{
Estudo sobre as relações entre gerenciamento de riscos em projetos, gestão do conhecimento e tomada de decisões
}

\author{
Study on the relationship between project risk management, knowledge \\ management and decision-making
}

\author{
Domingos Márcio Rodrigues Doutor em Informática e Gestão do Conhecimento, Programa de Pós-Graduação em \\ Napolitano Informática (PPGI-UNINOVE), Brasil - d.napolitano@uni9.pro.br \\ Marcelo Albano Mestrando em Informática e Gestão do Conhecimento, Programa de Pós-Graduação em \\ Informática (PPGI-UNINOVE), Brasil - mfalbano3@gmail.com \\ Marcos Antonio Gaspar Doutor e Administração, Programa de Pós-Graduação em Informática (PPGI-UNINOVE), Brasil \\ - marcos.antonio@uni9.pro.br \\ Renato José Sassi Doutor em Engenharia Elétrica, Programa de Pós-Graduação em Informática (PPGI-UNINOVE), \\ Brasil-sassi@uni9.pro.br
}

\section{RESUMO}

Muitas organizações são constantemente estimuladas a inovar em seus processos, produtos e serviços, diferenciando-se da concorrência para conquistar a preferência dos clientes. Uma das formas de inovar é a consecução de projetos que buscam renovar-se frente ao mercado. Não obstante, a gestão desses projetos é necessária para o desenvolvimento de conhecimentos que possam ser utilizados na gestão dos riscos em projetos desenvolvidos pelas empresas. Nesse contexto apresentado, formulou-se a seguinte questão de pesquisa: Quais as relações teóricas entre os processos de gerenciamento de riscos em projetos, da gestão do conhecimento e da tomada de decisão? E, no intuito de responder tal questão, estabeleceu-se o objetivo que foi analisar as relações teóricas entre o gerenciamento de riscos em projetos, gestão do conhecimento e a tomada de decisões, por meio da análise da produção acadêmica sobre estes três elementos. Para tanto, foi realizada uma pesquisa aplicada de caráter exploratório. Em primeiro lugar foram analisadas as estruturas dos três construtos propostos pelos principais autores, para identificar as relações entre elementos constituintes. Em uma segunda etapa, foi realizado um estudo bibliométrico para confirmar as relações identificadas na produção acadêmica. Como resultado, identificaram-se relações teóricas reunidas em um modelo conceitual que apresenta as principais variáveis e respectivos componentes da temática pesquisada. Além disso, o modelo proposto também agrupa as variáveis e respectivos componentes, proporcionando uma visão abrangente das inter-relações existentes entre os temas enfocados, até então independentes entre si, verificou-se também que existem poucas pesquisas sobre o tema, sendo uma problemática que merece atenção de trabalhos futuros.

Palavras-chave: Gerenciamento de Projetos; Gerenciamento de Riscos em Projetos; Gestão do Conhecimento; Tomada de Decisão; Análise Bibliométrica.

\begin{abstract}
Many organizations are constantly encouraged to innovate in their processes, products and services, thus differentiating themselves from the competition and in order to win customer preference. One of the ways to innovate is to achieve projects that seek to renew themselves in the market. Nevertheless, the management of these projects is necessary for the development of knowledge that can be used in risk management in projects developed by companies. In this context, the following research question was formulated: What are the theoretical relationships between project risk management, knowledge management and decision-making processes? In order to answer this question, we studied the theoretical relationships between project risk management, knowledge management and decision making through the analysis of academic production on these three elements. An exploratory applied research was performed. Firstly, the structures of the three constructs proposed by the main authors were analyzed to identify the relationships between the constituent elements. Then, a bibliometric study was performed to confirm the relationships identified in the academic production. As a result, we identified theoretical relationships gathered in a conceptual model that presents the main variables and respective components of the researched theme. In addition, the proposed model also groups the variables and their components, providing a comprehensive view of the interrelationships between the hitherto independent and focused themes. We also verified that there is little research on the topic and that it deserves further studies.
\end{abstract}

Keywords: Project management; Project Risk Management; Knowledge Management; Decision Making; Bibliometric Analysis.

Recebido em 20/08/2019. Aprovado em 23/09/2019. Avaliado pelo sistema double blind peer review. Publicado conforme normas da APA. http://dx.doi.org/10.22279/navus.2020.v10.p01-20.1056 


\section{INTRODUÇÃO}

O ambiente de negócios sempre foi caracterizado por desafios às mudanças impostas pela competitividade. Isso implica que as organizações patrocinem iniciativas estratégicas que demandam um amplo conjunto de conhecimentos, além de capacidade de organização e de tomada de decisões eficazes. Uma das alternativas para responder às mudanças é a utilização de modelos de gestão, entre eles destacamse a Gestão do Conhecimento e o Gerenciamento de Projetos, que podem ser conduzidos de forma simbiótica pela organização.

Neste contexto, a gestão das organizações depende cada vez mais de conhecimentos para garantir a orientação estratégica e o desempenho, fenômeno observado, por diversos pesquisadores, dentre os quais pode-se destacar: Ferraresi e Santos (2014), que investigaram as relações entre a gestão do conhecimento, a inovatividade, a orientação estratégica e o desempenho organizacional e Da Silva Nascimento e Sousa Júnior (2019) que elaboraram um modelo conceitual relacionando os construtos capital intelectual, gestão do conhecimento e sustentabilidade.

Ainda no âmbito acadêmico, porém consoante à temática gerenciamento de projetos, o gerenciamento de riscos é uma das maiores preocupações das organizações contemporâneas. Sendo assim, há um foco no estudo da sua relação com o sucesso dos projetos (Rabechini Jr \& Carvalho, 2012).

A abordagem da gestão de conhecimento como um recurso estratégico foi objeto de estudos de autores como Penrose (1959), Barney (1991), Grant (1996), Peteraf (1993) e Wernerfelt (1984). Outros autores estabeleceram uma estrutura para a sua gestão, como Nonaka e Takeuchi (1997), que determinam ciclos para que o conhecimento seja capturado expandido e desenvolvido no contexto de uma organização.

Ferraresi e Santos (2014) reforçam ainda que o conhecimento deve ser: a) criado e capturado, sendo aplicado para alcançar os objetivos organizacionais; b) compartilhado, convertido, organizado e disseminado entre as pessoas na organização e, por fim; c) aplicado pela organização. Tais elementos caracterizam a essência da gestão do conhecimento eficaz (Dalkir, 2017). Neste contexto, a gestão do conhecimento se apresenta como um elemento de valor estratégico para o tomador de decisões. No entanto, saber lidar com o sistema de gestão de conhecimento é apenas parte do processo mais abrangente de tomada de decisão (Wiig, 2003).

O estudo da decisão envolve a definição dos seus componentes das organizações. March (1991) define o processo de decisão como um ato intencional, caracterizado pelos seguintes elementos: 1) um conjunto de alternativas; 2 ) um conjunto de consequências dessas alternativas; 3 ) uma ordem de preferência entre as alternativas e suas consequências; e 4) uma regra para a escolha entre as alternativas. Complementando essa visão, Witte (1972) propôs uma ordenação clássica dos processos decisórios, partido da coleta de informações, passando pelo desenvolvimento de alternativas e seleção de alternativas e, encerrando com a escolha da alternativa. Um processo similar foi proposto por Mintzberger et al. (1976), que estabelece uma estrutura da tomada de decisão em uma abordagem estratégica. Mais recentemente, llevbare et al. (2014) propõem a técnica de roadmapping como uma ferramenta para desenvolver conhecimentos sobre riscos de projetos de tecnologia e possibilitar maior atenção ao seu tratamento.

Para Simon (1955) a racionalidade limitada, que considera como limitadores a tomada de decisão a capacidade de processamento de informações e do grau conhecimento sobre o ambiente da decisão é ocasionada por condições de riscos e incertezas nos processos decisórios que têm sua complexidade amplificada.

A eficácia de uma decisão está ligada aos processos empregados na escolha da melhor alternativa (Dean Jr \& Sharfman, 1996) que podem ser caracterizados por processos para tomada de decisão que são desenvolvidos por meio da aquisição de conhecimento e aprendizado, do estabelecimento de relações de causa e efeito das respectivas alternativas, variáveis estas verificadas empiricamente por Brinckmann et al. (2019), que avaliaram as relações de decisões de planejamento com características de capital humano das organizações.

Eisenhardt (1989) pesquisou ambientes nos quais as organizações precisam de decisões rápidas e eficazes para garantir sua sobrevivência. A autora verificou que a capacidade de analisar informações, definir 
alternativas e integrar decisões estratégicas com planejamento tático são características essenciais para os tomadores de decisão.

De acordo com Projetct Management Insitute - PMl (2017), forças como expectativas de clientes, desenvolvimento de novos produtos, busca por eficácia e eficiência levam as empresas a implementar iniciativas com o emprego de técnicas de gerenciamento de projetos, que por sua vez estão sujeitas a eventos incertos que podem afetar o sucesso destas iniciativas.

Tais eventos, denominados riscos, demandam ferramentas para seu gerenciamento que foram desenvolvidas para gerenciar as ameaças e oportunidades dos projetos contribuindo para que o gerente de projetos possa decidir como tratar os riscos (Kerzner, 2011).

Assim, é possível afirmar que o gerenciamento de riscos envolve a tomada de decisão, pois inclui identificar e analisar os riscos e bem como escolher as ações necessárias. Portanto, as práticas de gerenciamento de riscos implicam em ampliar as chances de atingir os objetivos do projeto (Kerzner, 2011), relação que foi verificada também por Carvalho e Rabechini (2012), bem como por Raz, Shenhar e Dvir (2002) e lbbs e Kwak (2000).

Ainda que os mencionados autores tenham destacado a influência positiva do gerenciamento de riscos quando aplicado aos projetos, observa-se paradoxo, pois se esses estudos verificam a influência positiva do gerenciamento de riscos nos resultados dos projetos (Rabechini Jr \& Carvalho, 2012; Raz \& Michael, 2001), no entanto, que sua adoção tem sido baixa (Rabechini Jr \& Carvalho, 2012; Ibbs \& Kwak, 2000, Raz, Shenhar e Dvir, 2002).

Dentro deste contexto, Zwikael e Ahn (2011) identificaram cinco obstáculos para a adoção de práticas de gerenciamento de riscos que são: limitadas variedade de ferramentas, emprego equivocado, ferramentas existentes de uso complexo, limitada autonomia dos gerentes de projetos e insatisfação com os resultados das ferramentas.

Diante das evidências anteriormente expostas verifica-se que a influência da gestão do conhecimento no gerenciamento de riscos é vista como crucial, conforme pode-se verificar em Cagliano, Grimaldi e Rafele (2015), para os quais o conhecimento é visto como um elemento fundamental para uma atitude em relação ao gerenciamento de riscos do projeto. Isto porque a aquisição e organização sistemáticas da informação é um passo necessário para passar de um conhecimento subjetivo sobre risco, que deve ser extraído de especialistas, para um conhecimento objetivo e de fácil acesso, formando a condição para uma análise quantitativa de riscos.

Tendo em vista os preceitos teóricos ora apresentados, bem como suas implicações práticas, estabeleceu à seguinte pergunta de pesquisa: 'Quais as relações teóricas entre os processos de gerenciamento de riscos em projetos, da gestão do conhecimento e da tomada de decisão?'.

Em função da pergunta de pesquisa, o objetivo deste trabalho foi analisar as relações teóricas entre o gerenciamento de riscos em projetos, gestão do conhecimento e a tomada de decisões. Para atender ao objetivo proposto para este estudo, foi desenvolvido um modelo conceitual para estudos gerenciamento de riscos em projetos, da gestão do conhecimento e da tomada de decisão, a partir de uma revisão sistemática da literatura (Gil, 2008), a partir da coleta e análise de dados secundários, decorrentes de publicações científicas tendo como base os seguintes construtos: gerenciamento de riscos em projetos, gestão do conhecimento e a tomada de decisões.

A revisão sistemática da literatura foi realizada em duas etapas, na primeira etapa realizou-se uma revisão de tipo narrativa (Paré, et al. 2015) que se caracteriza por empregar uma base de informações levantadas sem um critério de busca estreito, possibilitando a verificação de conceitos mais amplos, mas que possibilitou a formulação inicial do modelo conceitual.

Em uma segunda etapa foi realizada uma Meta-análise, que emprega métodos mais rígidos de extração e análise quantitativa dos dados bibliográficos, tendo como resultado uma avaliação menos sujeita à vieses dos pesquisadores.

A segunda etapa foi realizada em um conjunto de dados sobre artigos científicos encontrados na base de dados Web of Science (WoS) buscando por artigos envolvendo os três construtos em todas as suas possíveis 
combinações e um total de 1.332 artigos publicados entre 2010 e 2019. A seguir, apresenta-se essa lacuna, que posteriormente será analisada durante a discussão de resultados deste trabalho.

Cerca de $46 \%$ dos artigos desta base foram encontrados com a combinação das palavras-chave 'tomada de decisão' (decision making) e 'gestão do conhecimento' (knowledge management). Considerandose esta mesma amostra, 35\% dos resultados foram obtidos com a combinação das palavras-chave tomada de decisão e gerenciamento de projetos (project management) e 14\% correspondem à combinação das palavraschave 'gerenciamento do conhecimento' e 'gerenciamento dos projetos'. Tais resultados demonstram que há uma relação teórica que vem sendo continuamente investigada entre as palavras-chave mencionadas.

Entretanto, apenas 3\% da amostra corresponde à combinação das palavras-chave 'gerenciamento do conhecimento' e 'gerenciamento de projetos', outros 1,5\% correspondem à combinação das palavras-chave 'gerenciamento do conhecimento' e 'gerenciamento de riscos em projetos' e apenas três artigos são referentes às palavras-chave 'gerenciamento do conhecimento' e 'gerenciamento de riscos em projetos' (project risk management), tendo sido encontrado apenas um artigo corresponde à pesquisa da intersecção das palavraschave 'tomada de decisão', 'gerenciamento do conhecimento' e 'gerenciamento de riscos em projetos'.

Esta lacuna de pesquisa ficou evidenciada em relação às palavras-chave 'tomada de decisão', 'gerenciamento do conhecimento', 'gerenciamento de projetos' e/ou 'gerenciamento de riscos em projetos' o que, portanto, justifica a formulação do modelo conceitual ora proposto neste trabalho visando uma contribuição para estas áreas de conhecimento.

A principal contribuição deste trabalho foram a proposição de um modelo conceitual para estudos gerenciamento de riscos em projetos, da gestão do conhecimento e da tomada de decisão que mostrou tratarse de uma lacuna de pesquisa, que pode ser empregada em futuras pesquisa na área.

\section{REFERENCIAL TEÓRICO}

O referencial teórico foi organizado de forma a apresentar os três principais conceitos envolvidos no objeto deste trabalho, que são Tomada de Decisão, Gerenciamento do Conhecimento e Gerenciamento de Riscos em Projetos.

\subsection{Tomada de Decisão no Processo Decisório}

As decisões representam um importante elemento no resultado das organizações, mas são permeadas por incertezas, complexidades e ambiguidades inerentes aos ambientes em que as empresas atuam. Crises financeiras, competição e a globalização desafiam os executivos, aumentado o impacto dos riscos na tomada de decisão, demandando por processos decisórios cada vez mais eficazes, resultando em melhores resultados, permitindo o sucesso mesmo num contexto com recursos escassos (Kerzner, 2011).

Quanto maiores forem as incertezas, os processos de gerenciamento de riscos se mostram mais desafiadora, o que implica num fenômeno que foi definido por Simon (1955) como a racionalidade limitada. Tal conceito que se diferencia da abordagem clássica da tomada de decisão racional por considerar limitações em obter e processar informações precisas para que sejam tomadas as decisões (Simon, 1978). Para Simon (1955) a decisão no ambiente de negócios não é tomada objetivando uma solução ótima, mas sim solução satisfatória (satysfacing).

A eficácia de uma decisão está ligada aos processos empregados na escolha da melhor alternativa (Dean Jr \& Sharfman, 1996) que podem ser caracterizados por processos para tomada de decisão desenvolvidos por meio do aprendizado, além do estabelecimento de relações de causa e efeito das respectivas alternativas, o que resulta em aperfeiçoamento e consequente sucesso de longo prazo (Radner, 1975).

A qualidade de uma decisão pode ser constituída pela percepção do tomador de decisão, podendo ainda ser mensurada pela satisfação com a decisão tomada, com a concordância com a decisão tomada, com a satisfação com os resultados da decisão e com a percepção de um processo que teve bom desempenho (Guillemette et al., 2014). 


\subsection{Gerenciamento de riscos em projetos}

Considerando-se o ambiente de negócios contemporâneo, Kerzner (2011) ressalta que as organizações são comumente confrontadas por fenômenos, tais como expectativas de clientes, desenvolvimento de novos produtos e busca por eficácia e eficiência. A resposta das organizações a esses fenômenos tem se voltado ao investimento em iniciativas inovadoras do negócio, conduzidas por meio de gerenciamento de projetos. O gerenciamento de projetos é uma ferramenta para que sejam atingidos os seus objetivos estabelecidos e, consequentemente, o sucesso de forma contínua.

Neste contexto, ferramentas para o gerenciamento de riscos é constituído por processos, ferramentas e técnicas para lidar com as ameaças, e muitas vezes estendidas às oportunidades dos projetos de forma a auxiliar o gerente de projetos nas decisões para tratar os riscos (Kerzner, 2011), o que envolve a escolha dentre alternativas para responder aos riscos. Assim sendo, é possível entender o gerenciamento de riscos como parte de um processo de decisão, o que inclui identificar e analisar os riscos e as ações necessárias para seu tratamento. Desse modo, adotar práticas de gerenciamento de riscos implica em aumentar as chances de sucesso do projeto (Kerzner, 2011), relação que foi verificada por Rabechini e Carvalho (2012), Raz, Shenhar e Dvir (2002) e lbbs e Kwak (2000).

Por outro lado, na visão de Chapman e Ward (2004), as melhores práticas de gerenciamento de riscos nem sempre atendem às necessidades de todos os projetos, havendo casos nos quais a sua aplicação não seja necessária. Porém, a credibilidade dos processos de gerenciamento de riscos em projetos depende do quão bem o time do projeto desempenhará as funções de identificar e quantificar eventos incertos, fator este que frequentemente está associado à falha deste processo (Williams, 1995).

A relação entre sucesso do projeto e adoção do gerenciamento de riscos foi verificada por Besner e Hobbs (2012), que consideram que tais práticas são aplicadas com mais frequência em projetos que envolvam internacionalização, complexidade, inovação e ainda em projetos de grande porte. Zwikael e Sadeh (2007) verificaram ainda haver relação entre o uso de práticas de gerenciamento de projetos no sentido de gerenciar os riscos.

Para Wideman (1992) e Ackintoye e MacLeod (1997), o gerenciamento de riscos em projetos é composto basicamente por quatro etapas: a) identificação; b) análise; c) avaliação e d) controle. Destaca-se a relevância da etapa de identificação, pois por um lado é a origem de todo o processo de gerenciamento de riscos e de cujos resultados dependem todas as etapas subsequentes. Não obstante, por outro lado tal relevância acaba por exigir um elevado grau de conhecimento e criatividade (Chapman \& Ward, 2004), demandando pela opinião de especialistas (Chapman, 1990). A Tabela 1 expõe a comparação das diversas abordagens de gerenciamento de riscos consultadas para a composição do referencial teórico deste tema.

\begin{tabular}{|c|c|c|c|c|}
\hline PMI (2017) & Conrow (2003) & $\begin{array}{c}\text { Chapman e Ward } \\
(2003)\end{array}$ & Cooper, et al. (2005) & $\begin{array}{c}\text { Pich, et al. } \\
(2006)\end{array}$ \\
\hline \multirow{2}{*}{$\begin{array}{c}\text { Planejamento } \\
\text { de riscos }\end{array}$} & \multirow{2}{*}{ Planejar riscos } & Definir projeto & \multirow{2}{*}{ Estabelecer o contexto } & \multirow{3}{*}{ Identificação } \\
\hline & & Focar nos processos & & \\
\hline Identificação & \multirow{5}{*}{$\begin{array}{l}\text { Avaliação: } \\
\text { Identificação } \\
\text { Análise }\end{array}$} & $\begin{array}{c}\text { Identificação dos } \\
\text { riscos }\end{array}$ & Identificação dos riscos & \\
\hline Análise & & $\begin{array}{l}\text { Estruturação dos } \\
\text { riscos } \\
\end{array}$ & \multirow{2}{*}{ Analisar os riscos } & \multirow{4}{*}{$\begin{array}{c}\text { Avaliação e } \\
\text { Quantificação }\end{array}$} \\
\hline Qualitativa & & Definir dono do risco & & \\
\hline \multirow{2}{*}{$\begin{array}{c}\text { Análise } \\
\text { Quantitativa }\end{array}$} & & Estimar variância & \multirow{2}{*}{ Avaliar os riscos } & \\
\hline & & Estimar impactos & & \\
\hline $\begin{array}{l}\text { Plano de } \\
\text { respostas }\end{array}$ & Manipular riscos & Implementar planos & Tratar os riscos & $\begin{array}{l}\text { Estratégia de } \\
\text { resposta }\end{array}$ \\
\hline $\begin{array}{c}\text { Monitoramento } \\
\text { e Controle }\end{array}$ & $\begin{array}{c}\text { Monitoramento } \\
\text { de riscos }\end{array}$ & Gerenciar planos & $\begin{array}{c}\text { Monitorar e revisar, } \\
\text { Comunicar e consultar }\end{array}$ & $\begin{array}{c}\text { Documentação } \\
\text { e aprendizado }\end{array}$ \\
\hline
\end{tabular}

Tabela 1: Comparativo das abordagens de processos de gerenciamento de riscos

Fontes: adaptado de Conrow (2003); Cooper et al. (2005); Chapman; Ward (2003); Pich et al. (2006) e PMI (2018). 


\subsection{Gestão do conhecimento}

Dalkir (2017) explica que a gestão do conhecimento é uma área multidisciplinar que envolve diversos campos, dentre os quais é possível indicar: a) ciência organizacional, b) ciência cognitiva, c) linguística e linguística computacional, d) tecnologias de informação, tais como sistemas baseados em conhecimento, e) gestão da informação, sistemas eletrônicos de apoio ao desempenho e gestão e tecnologias de banco de dados.

O tema gestão do conhecimento tem sido amplamente estudado no contexto da Administração. Uma referência seminal é Penrose (1959), que explicou o efeito de fatores organizacionais como pesquisa e desenvolvimento, além de uma base tecnológica consistente, como aspectos fundamentais ao desenvolvimento das organizações. Um mecanismo observado pelo autor é de que a tecnologia, inserida em uma dinâmica promovida por pesquisa e desenvolvimento e suportada por esforços de vendas, leva a uma diversificação de mercados, o que seria essencial para a manutenção da lucratividade das empresas no longo prazo.

O conceito do conhecimento como um recurso, conforme a visão de Eisenhardt e Santos (2002), é expandido por Grant (1996), ao explorar os mecanismos de integração do conhecimento especializado na organização. Nesta abordagem, o conhecimento é considerado como residindo dentro do indivíduo. Assim, o papel principal da organização é aplicar o conhecimento em vez de criar o conhecimento em particular nas inovações.

Outro aspecto verificado é a adequação da estrutura hierárquica às necessidades da gestão do conhecimento e da tomada de decisão (Grant, 1996). Assim, o papel da organização está na governança do processo que utilizará o conhecimento tácito (individual e interno ao sujeito), que para Grant (1996) é o 'saber como' (know how), que funciona como a base para o conhecimento explícito (coletivo e externo), ou 'saber sobre' (know about).

Tomando-se como base a noção de racionalidade limitada (Simon,1955), Grant (1996) explica que se o ser humano possui limitações em adquirir, armazenar e processar o conhecimento, a figura de um especialista pode representar um importante recurso para a empresa. De forma empírica, Heath e Tversky (1991) verificaram que indivíduos com competência em um determinado tema conseguem lidar melhor com decisões em condições de incerteza e ambiguidade, em comparação com indivíduos sem o mesmo nível de preparo.

Para Wiig (1993), o conhecimento é constituído de percepções, entendimentos e know-how prático que são os recursos fundamentais que permitem ao ser humano funcionar de forma inteligente. Com o tempo, o conhecimento também é transformado em outras manifestações, tais como livros, tecnologia, práticas e tradições, o que ocorre em organizações de todos os tipos e na sociedade em geral. Quando utilizado de forma adequada, o conhecimento leva ao aumento da eficácia (Centobelli, Cerchione \& Esposito, 2017). Assim, o conhecimento é um ato inerente ao ser humano, porém, para que este se desenvolva da forma tácita para a explícita, ou seja para que possa evoluir do individual para o coletivo (organizacional), é necessária a instituição de processos que visam justamente operacionalizar este caminho (Nonaka \& Takeuchi, 1997; Ferraresi \& Santos, 2014 e Nonaka \& Toyama, 2007).

Na visão de Ceptureanu et al. (2018), a abordagem processual do conhecimento é fundamental, tanto em seus aspectos cognitivos como na transformação do conhecimento tácito em explícito. Porém, em relação aos aspectos de motivação para que esse processo ocorra, é comum que os executivos se empenhem na criação da infraestrutura necessária, apesar de parecer não haver uma clara compreensão de que também são necessários esforços ao integrar o uso do conhecimento armazenado (Dalkir, 2017).

Para Ferraresi e Santos (2014), a eficácia da gestão do conhecimento pode ser medida por meio do levantamento da percepção dos gestores. Assim é proposto que a gestão do conhecimento eficaz existe quando uma organização possui processos mensuráveis para: a) criar e capturar o conhecimento que será aplicado para alcançar os objetivos organizacionais; b) compartilhar, converter, organizar e disseminar o 
conhecimento entre as pessoas na organização; e c) aplicar o conhecimento para criar valor para a empresa e seus clientes.

\subsection{Relação entre Decisão, Gestão do conhecimento e Gerenciamento de Riscos}

Relacionando o conhecimento com a capacidade de tomada de decisão e o desempenho de uma organização, Wiig (2003) indica que o desempenho da empresa é determinado pela eficácia de como as situações são tratadas por toda a organização, havendo dependência de diferentes fatores. O primeiro e mais importante é a qualidade e disponibilidade de conhecimentos pertinentes. Alguns são bem conhecidos e são tratados como conhecimentos de rotina, por serem sistematizados na forma de códigos, procedimentos e regras (March, 1991). Os estudos de Perrow (1967) permitem compreender que a primeira resposta das organizações à incerteza é o estabelecimento de rotinas de busca de conhecimento para o tratamento das exceções de modo a normatizar a tomada de decisão. Porém, ambientes de alta incerteza caracterizados por elevado nível de exceções, bem como a dificuldade na busca de conhecimentos, leva as organizações a diminuírem este grau de normatização. Tais modelos envolvem outra categoria de conhecimentos, que se caracteriza por ser mais complexa e abstrata (Wiig, 1993).

Assim sendo, para lidar com diferentes tipos de situações de forma eficaz são necessários diferentes tipos de conhecimento para apoiar as principais tarefas de construção de sentido, a tomada de decisão e resolução de problemas, execução e acompanhamento (WIIG, 1993). Dessa forma, uma gestão de conhecimentos deliberada e sistemática está relacionada à entrega de um trabalho competente, demandado explicitamente por mecanismos de aprendizagem ou de inovação. Deste modo, a tomada de decisão fica caracterizada como resultante do conhecimento disponível (Wiig, 1993; Dalkir, 2017).

Para compreender a relação entre risco e conhecimento é preciso entender a essência do que é risco que, segundo o Project Management Institute - PMI (2017), é um evento cujo resultado pode comprometer o sucesso do projeto. A essência da gestão de riscos baseia-se em eventos que podem acontecer. Para reforçar tal entendimento é preciso considerar a contribuição de Knigth (1921), que estabeleceu o conceito de risco como uma incerteza mensurável, o que já pode ser considerado um conhecimento quando aplicado à gestão de projetos reais nas organizações.

A mensuração do risco, para o autor, poderia ser realizada com o uso de ferramentas probabilísticas, o que nem sempre é possível, seja por uma questão das informações disponíveis sobre a decisão a ser tomada, seja sobre como calcular as probabilidades das consequências (Knigth, 1921). Em função dessas restrições, mensurar o risco implica certo grau de conhecimento, bem como acesso a informações sobre os eventos incertos que permitirão sua previsão. Consequentemente, a incerteza está relacionada à capacidade de previsão de eventos futuros.

A observação das escolhas em jogos de azar permite avaliar o comportamento do tomador de decisão diante de eventos incertos que refletem o quanto se está preparado para tomar um rumo de ação (Ramsey, 1931). Tal observação eleva a discussão sobre o risco além de uma questão probabilística, mas também indica sua estreita ligação às características inerentes de cada indivíduo, pois em suas escolhas, o tomador de decisão parte de uma reflexão ou uma inferência para a escolha a ser tomada, fundamentando um grau de crença (degree of beliefs). A noção geral deste fenômeno foi definida por Keynes (1921) como uma relação $a=a / h$, na qual 'a' são conclusões e ' $h$ ' são premissas, desde que exista um conhecimento de ' $h$ ' que justifique uma crença racional em ' $a$ ', sendo que este pode ser medido por um grau de crença ' $a$ ', o qual pode ser interpretado como um tipo de conhecimento tácito de especialistas.

Face ao exposto, quando se diz que um evento é provável ou certo, é estabelecido um grau de crença para a ocorrência deste evento, ou ainda, é declarado que algum conhecimento para tal assertiva torna-se explícito. Portanto, ao lidar com os riscos em projetos, serão identificados eventos que podem influenciar no seu sucesso (Kerzner, 2011), sobre os quais será possível ou não atribuir uma probabilidade com base em um grau de crença, de acordo com as proposições de Ramsey (1931) e Keynes (1921).

Processos decisórios exercessem um efeito positivo no resultado da implementação de decisões estratégicas, uma vez que quando uma incerteza é identificada pode ser tratada de modo mais seletivo e 
diligente. Não obstante, quando uma certeza é verificada, um conjunto de metodologias para o tratamento de problemas (problem-solving) é empregado (Klingebiel \& De Meyer, 2014).

Um mapa básico das práticas envolvidas na gestão de riscos pode ser observado no PMBoK (PMI, 2017), que pode ser entendido como o processo básico para gerenciamento do risco em projetos e cujas etapas básicas estão representadas na Figura 1.

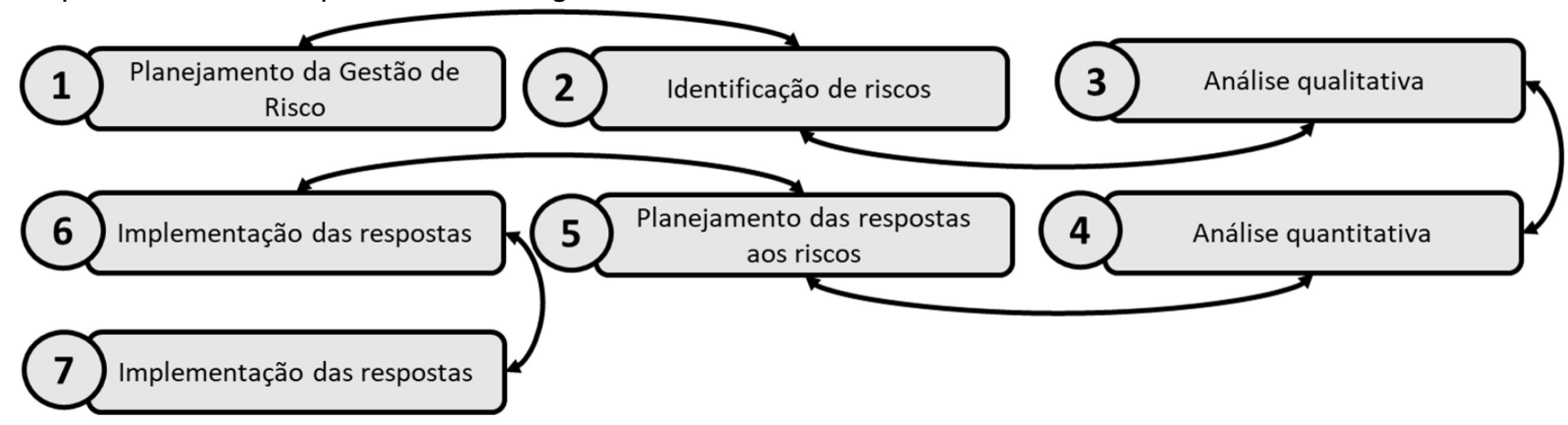

Figura 1: Processos da gestão de riscos em projetos. Fonte: adaptado pelos autores de PMI (2017).

\section{METODOLOGIA DE PESQUISA}

Considerando-se o contexto deste trabalho, classifica-se a pesquisa como aplicada, com um caráter exploratório, conforme definido por Sampieri, Collado e Lucio (2013). A seguinte pergunta de pesquisa é apresentada: 'Quais as relações teóricas entre os processos gerenciamento de riscos em projetos, da gestão do conhecimento e da tomada de decisão?'.

Deste modo, estabeleceu-se como objetivo analisar as relações teóricas entre o gerenciamento de riscos em projetos, gestão do conhecimento e a tomada de decisões. Para consolidar os resultados dessa análise elaborou-se um modelo conceitual, que possibilita a compreensão dos resultados da análise de modo agregado. Os componentes deste modelo foram identificados por meio de uma revisão sistemática da literatura. A proposição de modelos conceituais desenvolvidos por meio de revisões da literatura tem sido empregada por autores na área de gestão do conhecimento que visaram estabelecer as bases teóricas de temáticas como as relações capital humano, gestão do conhecimento e sustentabilidade (Da Silva Nascimento \& Sousa Júnior, 2019) e a transferência do conhecimento em clusters (Fioravanti \& Macau, 2017).

Para Brereton et al. (2007), revisões sistemáticas da literatura possibilitam sumarizar evidências que suportem pesquisas sobre um determinado fenômeno. Conforme se verificou na seção de fundamentação teórica deste trabalho, há diversas discussões que possibilitam verificar relações individuais entre os construtos do modelo teórico em estudo.

Inicialmente foi realizada uma revisão sistemática da literatura do tipo narrativa (Paré, et al. 2015) onde os artigos coletados por meio de critérios mais amplos que possibilitaram a proposição do modelo conceitual. Para eliminar possíveis efeitos de viés dos autores, foi realizada uma segunda coleta e análise de dados guiada por critérios mais estreitos e baseada em análises quantitativas, o que foi definido por Paré et al. (2015) como meta-análise. O modelo conceitual pode ser detalhado, até alcançar o estágio de sua operacionalização por meio de um instrumento de pesquisa a ser aplicado empiricamente.

O processo de narrativa foi executado iniciando-se por uma pesquisa bibliográfica baseada nos principais autores, na qual foram levantadas pesquisas relevantes no sentido de permitir a definição e compreensão dos construtos e suas relações sob uma perspectiva teórica. A seguir, foram estabelecidos os construtos Gestão do Conhecimento, Tomada de Decisão e Gerenciamento de Riscos em Projetos.

No processo de meta-análise estes construtos foram usados como palavras-chave que foram combinadas entre si para verificar as relações entre artigos recuperados na base de dados Web of Science em pesquisa realizada em junho de 2019, na qual foram extraídas informações como publicações, citações e 
referências, dentre outras que foram verificadas por meio de análises bibliométricas realizadas em linguagem R e empregando o pacote Bibliometrix (Aria \& Cuccurullo, 2017).

Os resultados obtidos com o auxílio destes softwares foram analisados com o intuito de investigar as relações entre os construtos, características das publicações e análise histórica dos registros encontrados. Por fim, executou-se a elaboração e validação prévia do modelo conceitual. Tal processo pode ser visualizado na Figura 2.

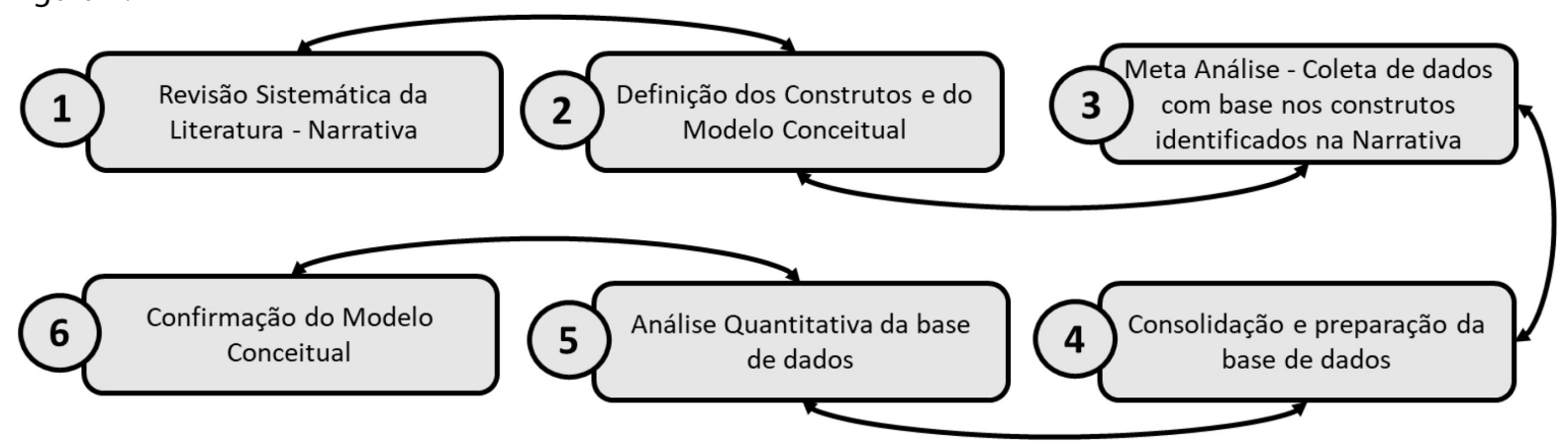

Figura 2: Fluxo do processo de pesquisa que estrutura os procedimentos metodológicos Fonte: elaborado pelos autores com base em Gil (2001) e Teóphilo e Martins (2010).

\section{APRESENTAÇÃO E DISCUSSÃO DOS RESULTADOS}

Observando a produção dos principais autores nas áreas de gerenciamento de riscos em projetos, gestão do conhecimento e a tomada de decisão, verificam-se que que existem relações entre seus componentes estruturais. Nesta seção em primeiro lugar apresentam-se as principais evidências dessas relações presentes nas teorias propostas pelos principais autores, para a seguir confirmar se essas relações estão também presentes em um conjunto de artigos extraídos da base de dados Web of Science (WoS). Por meio de métodos bibliométricos, estas relações puderam ser mensuradas e visualizadas em termos de extensão dos conceitos envolvidos e organização temporal.

\subsection{Resultados da Pesquisa Bibliográfica dos principais autores}

Para definir o construto envolvendo a gestão de riscos em projetos propõe-se a compreensão da estrutura do elemento gestão do conhecimento, bem como do elemento gestão de riscos, ambos associados ao escopo de projetos. Em primeiro lugar, a caracterização do risco como um conhecimento se dá pelas definições sobre risco de Knigth (1921), que definiu o risco como uma incerteza que se pode medir. Em complemento à caracterização do risco, as definições de Wideman (1992) e Hillson (2002) também foram consideradas, por estabelecerem o risco como o resultado de uma probabilidade e impacto de um evento que possa afetar o sucesso de um projeto. De forma mais avançada, considera-se ainda a visão de Keynes (1921), para quem a probabilidade se define como um conhecimento sobre um determinado evento. Deste modo, a pesquisa deve prever os elementos do risco e das decisões a ele envolvidas como aspectos a serem geridos num processo de gestão do conhecimento voltada à gestão de projetos.

Neste contexto percebem-se as relações entre os conceitos previstos no referencial bibliográfico pesquisado para o estabelecimento da plataforma teórica deste estudo, cuja representação gráfica é apresentada na Figura 3. 


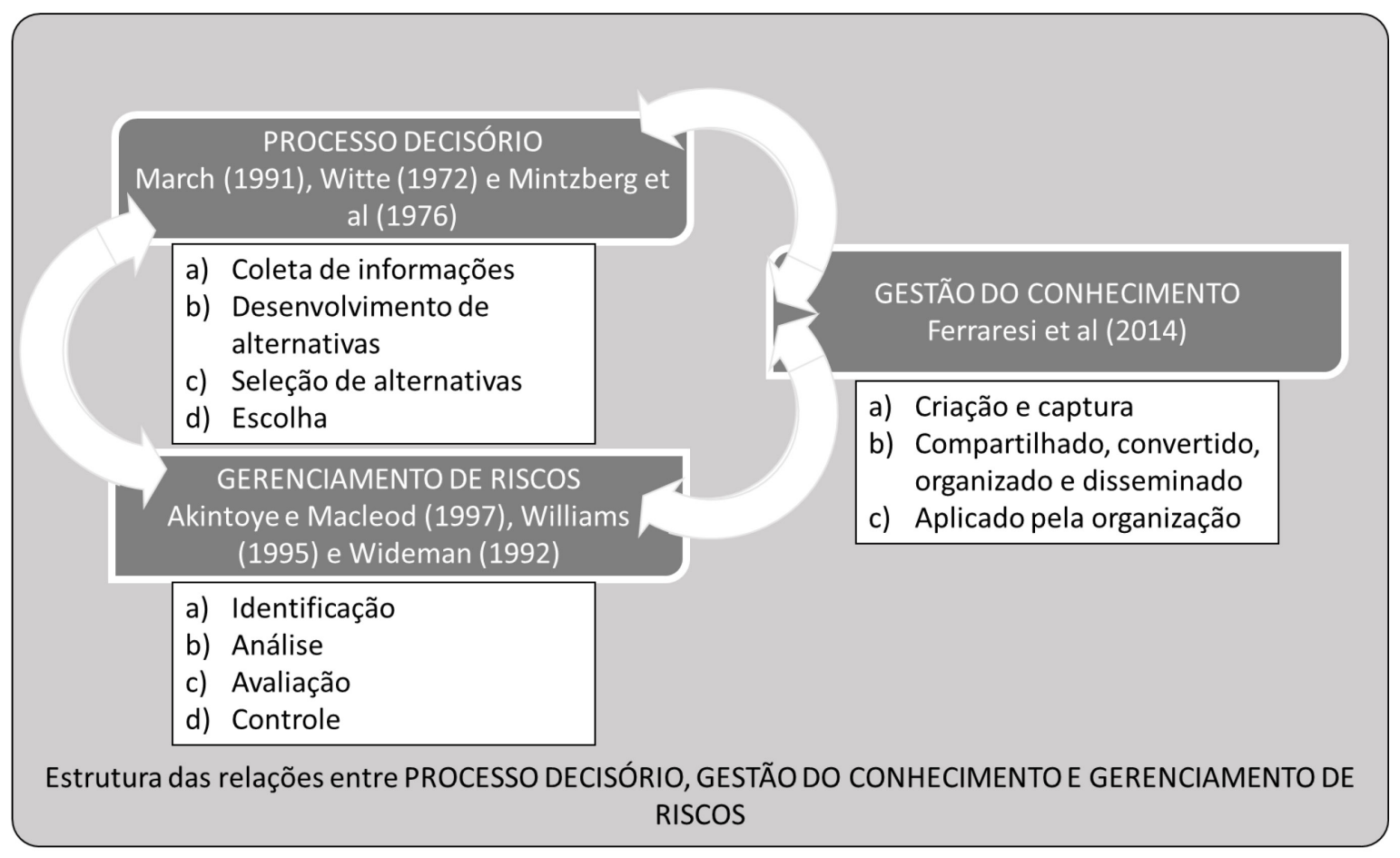

Figura 3: Estrutura do modelo conceitual gestão do conhecimento em riscos de projetos Fonte: elaborado pelos autores com base no referencial teórico pesquisado.

A estrutura da Figura 3 procura mostrar as relações entre os três elementos centrais deste trabalho iniciando pelo termo processo decisório destacam-se os elementos propostos por March (1991) e que define o processo decisório como uma ação intencional, caracterizada por quatro elementos: a) um conjunto de alternativas, b) um conjunto de suas consequências esperadas; c) uma ordem de preferência sobre para consequências e alternativas; e d) uma regra para a tomada de decisão, que permitirá escolher entre as alternativas.

Por outro lado, Mintzembeg et al. (1976) e Witte (1972) propuseram etapas para este processo como coleta de informações, desenvolvimento de alternativas e que permitem operacionalizar o processo decisório nas organizações.

Dentro da mesma estrutura verifica-se que Ferraresi et al. (2014) mostram que a gestão do conhecimento é efetiva quando é capaz de criar, capturar compartilhar, converter, compartilhar, disseminar e aplicar o conhecimento numa organização.

Portanto assumindo que o gerenciamento de riscos produz conhecimento sobre um conjunto de eventos que afetam a organização, e que esse conhecimento deve ser processado de modo a permitir uma tomada de decisão, que deve levar em conta uma série de alternativas e que objetiva garantir o melhor resultado para a organização.

Por fim, observando as características operacionais entre os processos descritos nas referencias mencionadas, pode-se compreender que existem relações entre estes elementos que formam um construto que possibilita propor e avaliar teorias referente às relações apresentadas, ao menos dentro da perspectiva das referências citadas.

Destaca-se que todos processos iniciam-se pela busca ou captura das informações, enquanto no gerenciamento de riscos o processo inicia-se pela identificação dos riscos e sua posterior análise (PMI, 2017), todos os processos iniciam-se pela coleta, identificação ou captura de conhecimento sobre riscos; em um segundo momento, é feita a avaliação e a análise, que possibilitam a determinação e seleção de alternativas no processo decisório, que devem ser compartilhadas, organizadas e disseminadas em conformidade com os processo da gestão de conhecimento, em seguida inicia-se a etapa de controle dos riscos, as escolhas entre as alternativas e sua disseminação pela organização. Este ciclo é apresentado na Figura 4. 


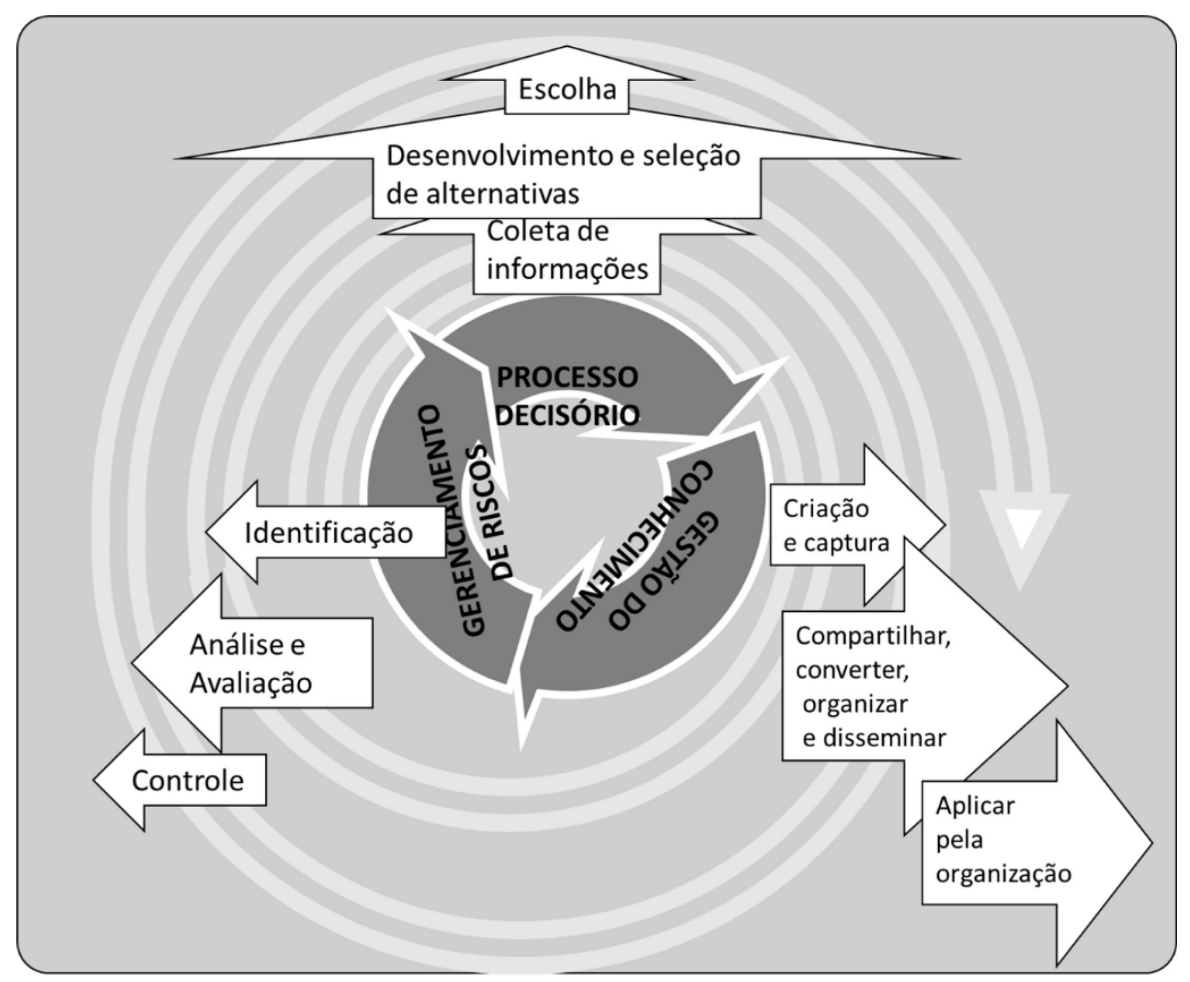

Figura 4: Visualização do Modelo conceitual proposto na forma de um ciclo. Fonte: elaborado pelos autores.

Uma vez verificadas as relações teóricas entre os conceitos apresentados, pode-se avaliar como operacionalizar o modelo conceitual, determinando as variáveis a serem observadas e o respectivo modelo de mensuração. O modelo ora proposto é apresentado na Figura 5.

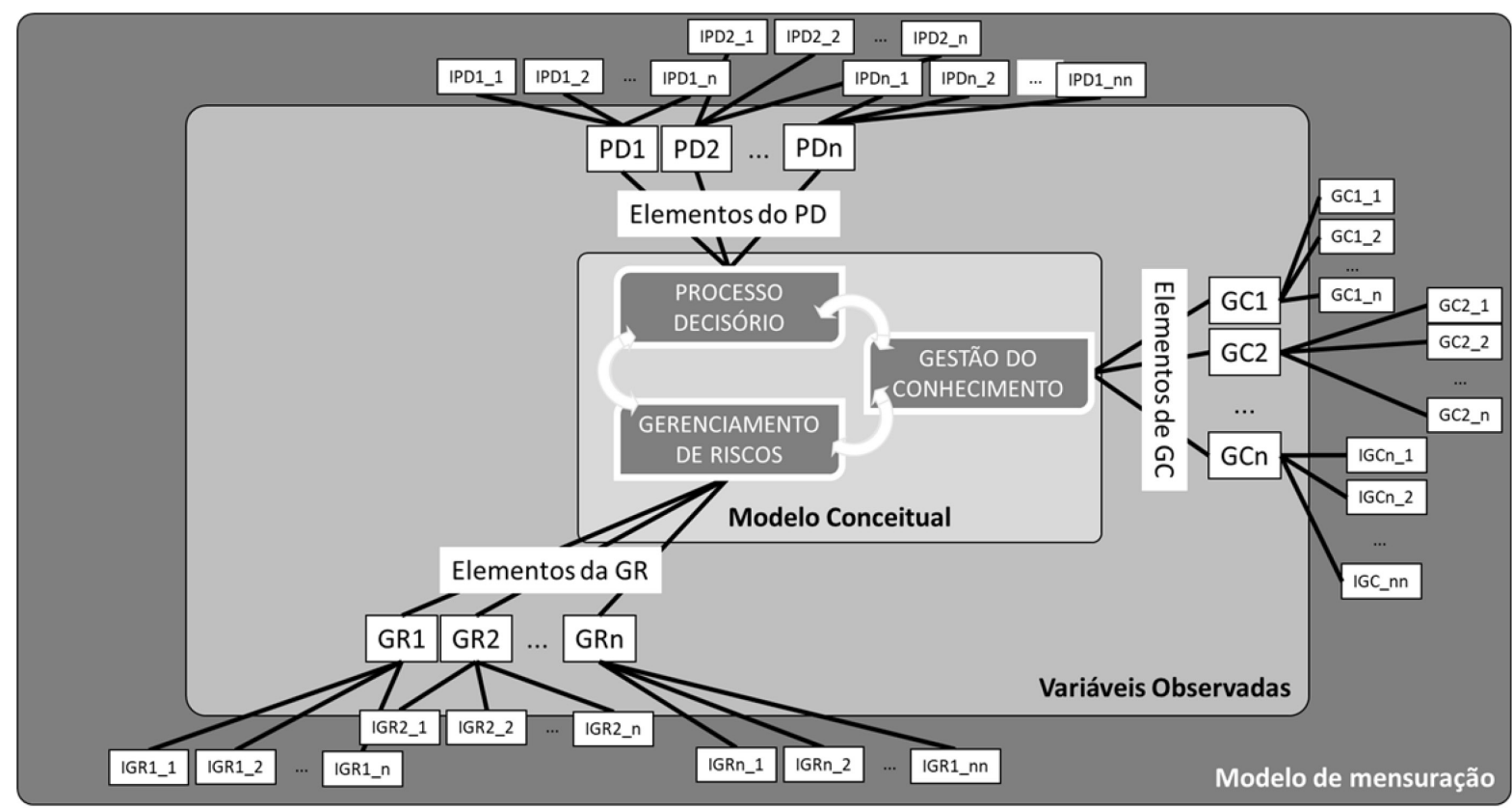

Figura 5: Operacionalização do Modelo conceitual proposto Fonte: elaborado pelos autores.

O que se pode verificar na Figura 5 é que o modelo conceitual proposto, pode ser desdobrado, até um modelo de mensuração, passando pelas variáveis observadas. Assim variáveis como captura, do 
conhecimento, disseminação, e outras podem ser avaliadas em termos de relações com outras variáveis como identificação e análise de riscos e as etapas do processo decisório.

Ao nível de mensuração, os elementos de cada um dos processos a serem observados, deve ser traduzido por indicadores, que podem ser qualitativos ou qualitativos, dependendo da forma como se pretende desenvolver a pesquisa, por meio de questionários aplicados nas organizações pesquisadas.

O modelo conceitual ora proposto provém da revisão da teoria e da reflexão sobre uma temática análise, conforme proposto por Gil (1999). Deste modo, pode-se avançar na pesquisa sobre a temática em estudo. Para estabelecer a estrutura teórica do modelo, a Tabela 2 apresenta as relações entre os autores pesquisados e os conceitos que compõem o modelo e construtos apresentados.

\begin{tabular}{|c|c|c|c|}
\hline Variável & $\begin{array}{l}\text { Compo- } \\
\text { nentes }\end{array}$ & Descrição & Autores \\
\hline \multirow{3}{*}{ 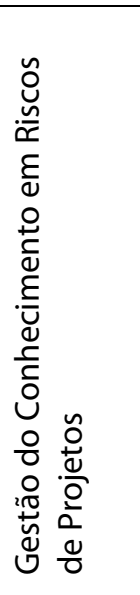 } & $\begin{array}{l}\text { Gestão de } \\
\text { Riscos em } \\
\text { Projetos }\end{array}$ & $\begin{array}{l}\text { A gestão e riscos é um processo que tem como } \\
\text { entradas elementos do planejamento de } \\
\text { projetos, o conhecimento do ambiente de } \\
\text { projetos, ferramentas e técnicas e como saída o } \\
\text { devido tratamento dos riscos identificados e de } \\
\text { seus potenciais impactos, por meio de ações } \\
\text { escolhidas entre as alternativas desenvolvidas. }\end{array}$ & $\begin{array}{l}\text { PMI (2017), Ward (1999), } \\
\text { Chapman e Ward (2003), } \\
\text { Cooper et al. (2003), Pich } \\
\text { et al. (2002), Hillson (2002) }\end{array}$ \\
\hline & $\begin{array}{l}\text { Processos } \\
\text { Decisórios }\end{array}$ & $\begin{array}{l}\text { Processos decisórios envolvem coleta de dados, } \\
\text { desenvolvimento e seleção de alternativas e a } \\
\text { escolha final. }\end{array}$ & $\begin{array}{l}\text { De Witte et al. (1972), } \\
\text { Mintzberg et al. (1976), } \\
\text { llevbare et al. (2014) }\end{array}$ \\
\hline & $\begin{array}{l}\text { Gestão do } \\
\text { Conheciment } \\
\text { o }\end{array}$ & $\begin{array}{l}\text { A gestão do conhecimento envolve processo } \\
\text { para criar captura disseminar e aplicar o } \\
\text { conhecimento nas organizações. }\end{array}$ & $\begin{array}{l}\text { Johansson et al. (2011), } \\
\text { Heath e Tversky (1991), } \\
\text { Ferraresi e Santos (2014), } \\
\text { Levibare et al. (2014) }\end{array}$ \\
\hline \multicolumn{2}{|c|}{ Eficácia da Decisão } & $\begin{array}{l}\text { O resultado de uma decisão eficaz está } \\
\text { relacionado com a implementação da } \\
\text { alternativa escolhida, com os resultados } \\
\text { percebidos e principalmente com a satisfação } \\
\text { do tomador de decisão com os resultados. }\end{array}$ & $\begin{array}{l}\text { Simon (1955) } \\
\text { Bernoulli (1954) } \\
\text { Dean e Scharfman (1993) } \\
\text { Dean e Scharfman (1996) } \\
\text { Guillemetti et al. (2014). } \\
\end{array}$ \\
\hline \multicolumn{2}{|c|}{ Estrutura da Decisão } & $\begin{array}{l}\text { O processo decisório é composto por um } \\
\text { conjunto de alternativas de decisão, cenários e } \\
\text { impactos ou ganhos. }\end{array}$ & $\begin{array}{l}\text { Simon (1955), Savage } \\
\text { (1972), Raiffa (1977), } \\
\text { Shimizu (2010) }\end{array}$ \\
\hline
\end{tabular}

Tabela 2: Elementos componentes do modelo conceitual proposto

Fonte: elaborado pelos autores com base no referencial teórico pesquisado.

\subsection{Resultados da Análise Bibliométrica}

Tendo em vista o modelo teórico proposto é importante demonstrar sua relevância e possibilidade de contribuição à academia e praticantes das organizações. Para tanto, realizou-se uma análise bibliométrica de modo a melhor dimensionar as relações entre os seus componentes. Os dados para esta análise foram obtidos em uma pesquisa realizada na base de dados Web of Science (WoS). Após a coleta, os dados foram analisados com o emprego de técnicas bibliométricas que permitiram avaliar a relevância da área e a capacidade de contribuição do modelo proposto.

Em primeiro lugar analisou-se as quantidades de artigos que retornaram da pesquisa no WoS para cada combinação de palavras-chave escolhidas, bem como as respectivas taxas anuais de crescimento da produção científica apresentadas na Tabela 3. 


\begin{tabular}{|l|c|c|}
\hline \multicolumn{1}{|c|}{ Palavras-chave } & $\begin{array}{c}\text { Quantidade } \\
\text { de artigos } \\
\text { WoS }\end{array}$ & $\begin{array}{c}\text { Taxa de crescimento } \\
\text { anual da produção } \\
\text { científica. }\end{array}$ \\
\hline $\begin{array}{l}\text { "knowledge management" AND ("decision making" OR } \\
\text { ("decision making") }\end{array}$ & 893 & $13,05 \%$ \\
\hline $\begin{array}{l}\text { "project management" AND ("decision making" OR ("decision } \\
\text { making") }\end{array}$ & 655 & $14,08 \%$ \\
\hline "knowledge management" AND "project management" & 249 & $12,10 \%$ \\
\hline $\begin{array}{l}\text { "project risk management" AND ("decision making" OR } \\
\text { ("decision making") }\end{array}$ & 43 & $13,65 \%$ \\
\hline $\begin{array}{l}\text { "knowledge management" AND "project management" AND } \\
\text { ("decision making" OR ("decision making") }\end{array}$ & 25 & $17,46 \%$ \\
\hline "knowledge management" AND "project risk management" & 7 & $14,87 \%$ \\
\hline $\begin{array}{l}\text { "knowledge management" AND "project riskmanagement" AND } \\
\text { ("decision making" OR ("decision making") }\end{array}$ & 1 & $\mathrm{~N} / \mathrm{A}$ \\
\hline Total & 1.873 & $17,66 \%$ \\
\hline
\end{tabular}

Tabela 3: Estrutura da amostra de dados coletada na base Web of Science. Fonte: elaborado pelos autores com base nos dados coletados.

Os resultados expostos na Tabela 3 demonstram que os três construtos, gestão do conhecimento, gerenciamento de riscos e tomada de decisão, de forma combinada ou individualmente, apresentaram taxas de crescimento anual de produção científica sempre superiores a $10 \%$ ao ano, indicando que há uma evolução neste campo de produção científica.

Por outro lado, quando se combinam dois dos três construtos, há uma variação no número de artigos que retornam da pesquisa no WoS, indicando que existem lacunas de pesquisa, o que pode ser observado pelo fato de que apenas um artigo foi recuperado em relação ao cruzamento dos termos associados "knowledge management" e "project risk management" AND ("decision making" OR ("decision making").

A seguir foi avaliada a rede de coocorrência de citações que, de acordo com Aria e Cuccurullo (2017), expõe as relações de similaridade entre uma amostra de artigos. A rede de coocorrência resultante da análise efetuada é apresentada na Figura 5.

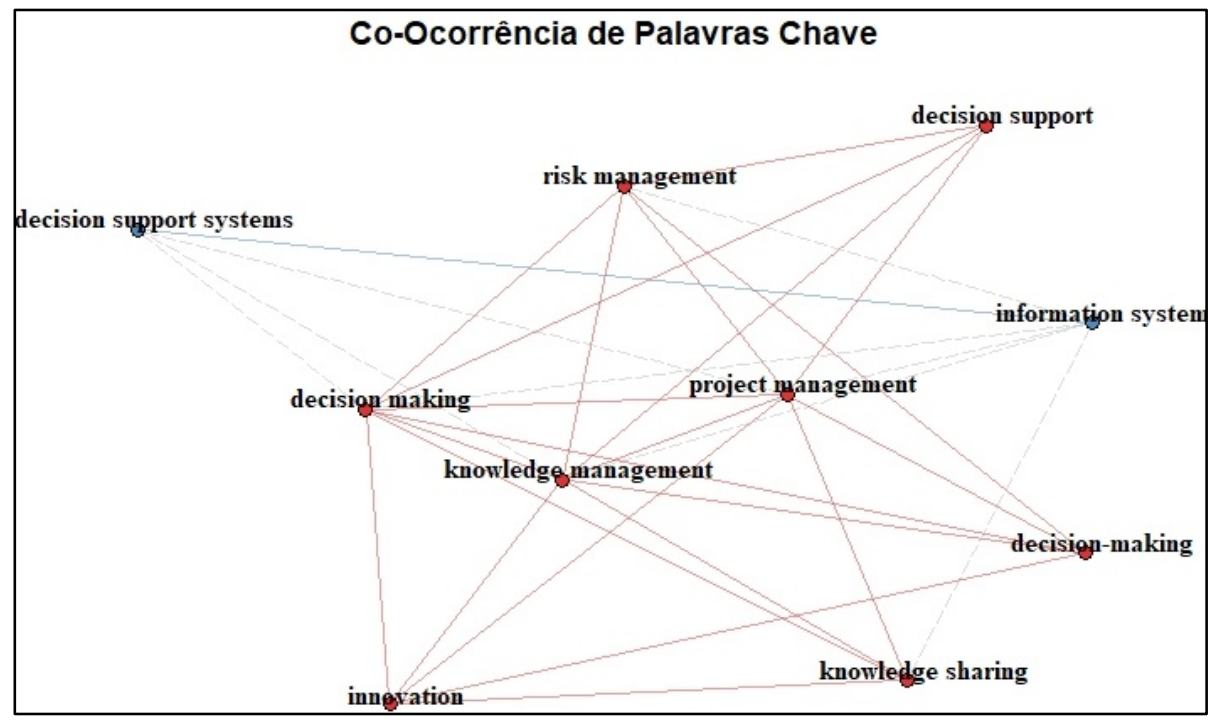

Figura 5: Rede de coocorrência de palavras-chave Fonte: elaborado pelos autores.

A rede de cocitações demostra as relações entre as palavras-chave empregadas pelos autores com maior frequência. Além das palavras-chave usadas, aparecem com grande frequência os termos "knowledgesharing", "innovation", "information systems" e "decision support", os quais denotam campos importantes nos quais as pesquisas da amostra observada vêm sendo desenvolvidas.

A seguir foi executada a verificação da análise da estrutura conceitual, que de acordo com Aria e Cuccurullo (2017), revela os conceitos por meio do emprego da técnica de multiescalonamento dimensional 
e clusterização (agrupamento), baseados na ocorrência de como as palavras-chave estão distribuídas em grupos. O mapa da estrutura conceitual da amostra analisada é apresentado na Figura 6.

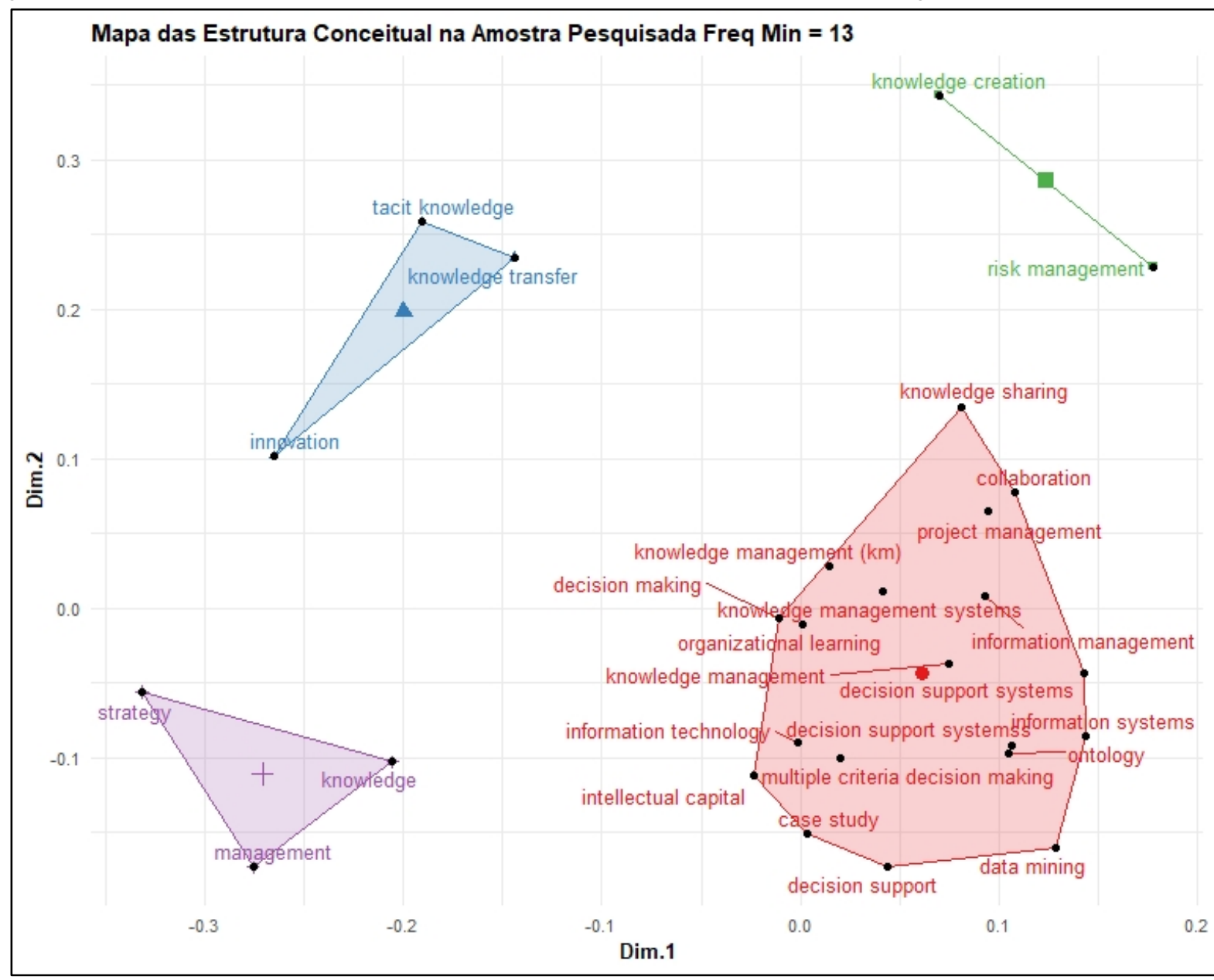

Figura 6: Mapa da estrutura conceitual da amostra pesquisada Fonte: elaborado pelos autores.

Foram verificados quatro grupos (clusters) no mapa da estrutura conceitual analisada. No principal cluster verificam-se as principais características que demonstram a estrutura dos conceitos formadores do modelo teórico proposto, no qual se destacam, além dos construtos em si, temas que sugerem possíveis elementos para novas pesquisas empregando modelo proposto entre elas: data minning, decision support systems, mutiple criteria decision making, knowledge management systems, intellectual capital.

Para entender como as pesquisas neste campo evoluíram em relação ao tempo, verificou-se a evolução da produção anual da amostra pesquisada apresentada na Figura 7. 


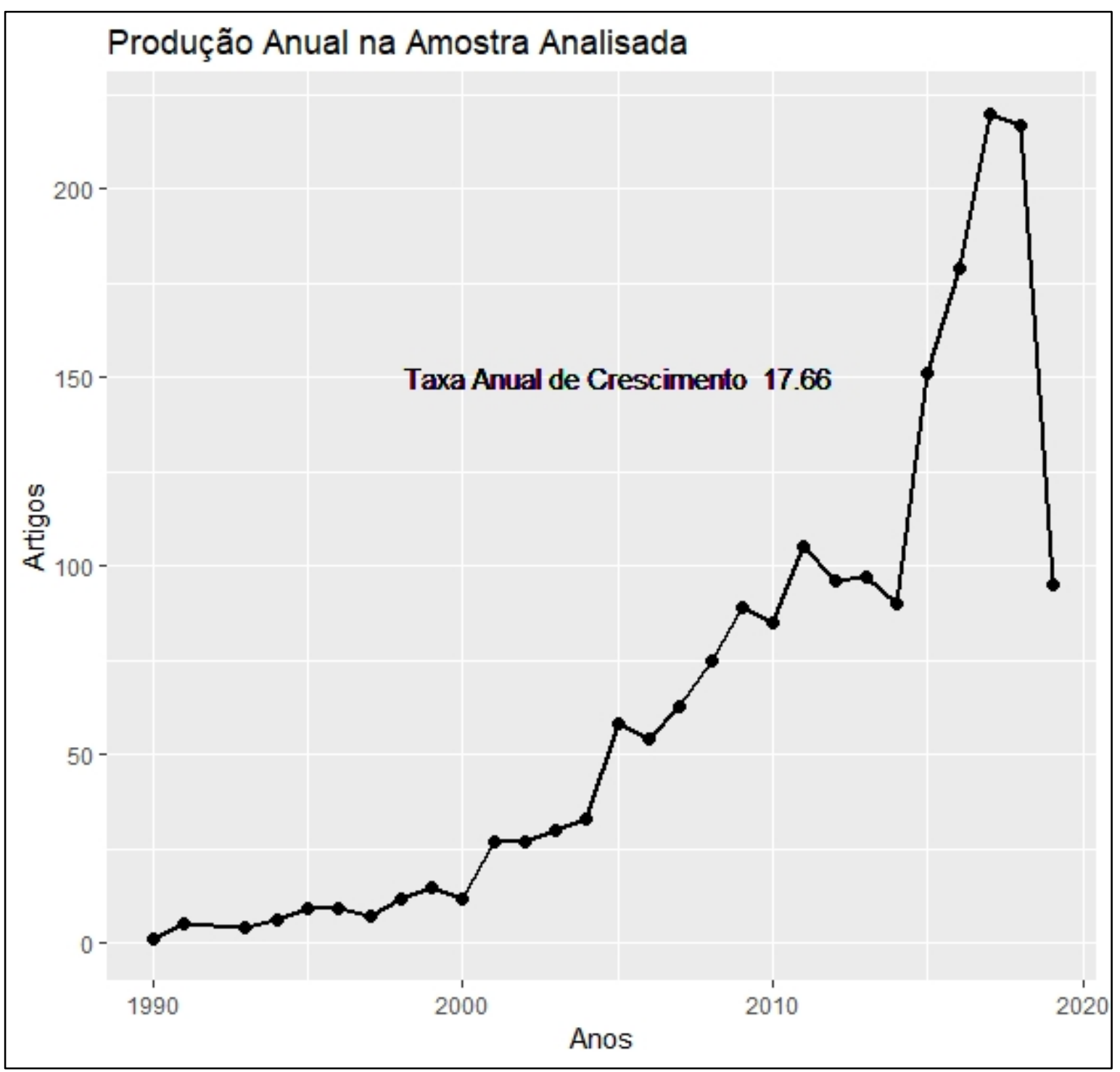

Figura 7: Produção anual da amostra analisada Fonte: elaborado pelos autores.

A curva de crescimento da produção anual exibe três períodos distintos. No primeiro período (1990 a 2005) verifica-se uma evolução a taxas mais modestas. No segundo período (2006 a 2015) inicia-se um processo de crescimento mais intenso, sendo que no terceiro período (a partir de 2016) nota-se uma evolução acelerada.

Face aos resultados apresentados, o estudo da amostra revelou que inicialmente as pesquisas eram mais genéricas e que ao longo do tempo novos termos foram sendo incorporados. Este movimento demonstra o aumento da amplitude de objetos de pesquisa, tornando assim este campo teórico cada vez mais abrangente em suas pesquisas. Portanto, para entender a evolução destes temas em uma dinâmica temporal, apresenta-se a Figura 8 a evolução temática da dos artigos retornados da pesquisa no WoS analisada. 


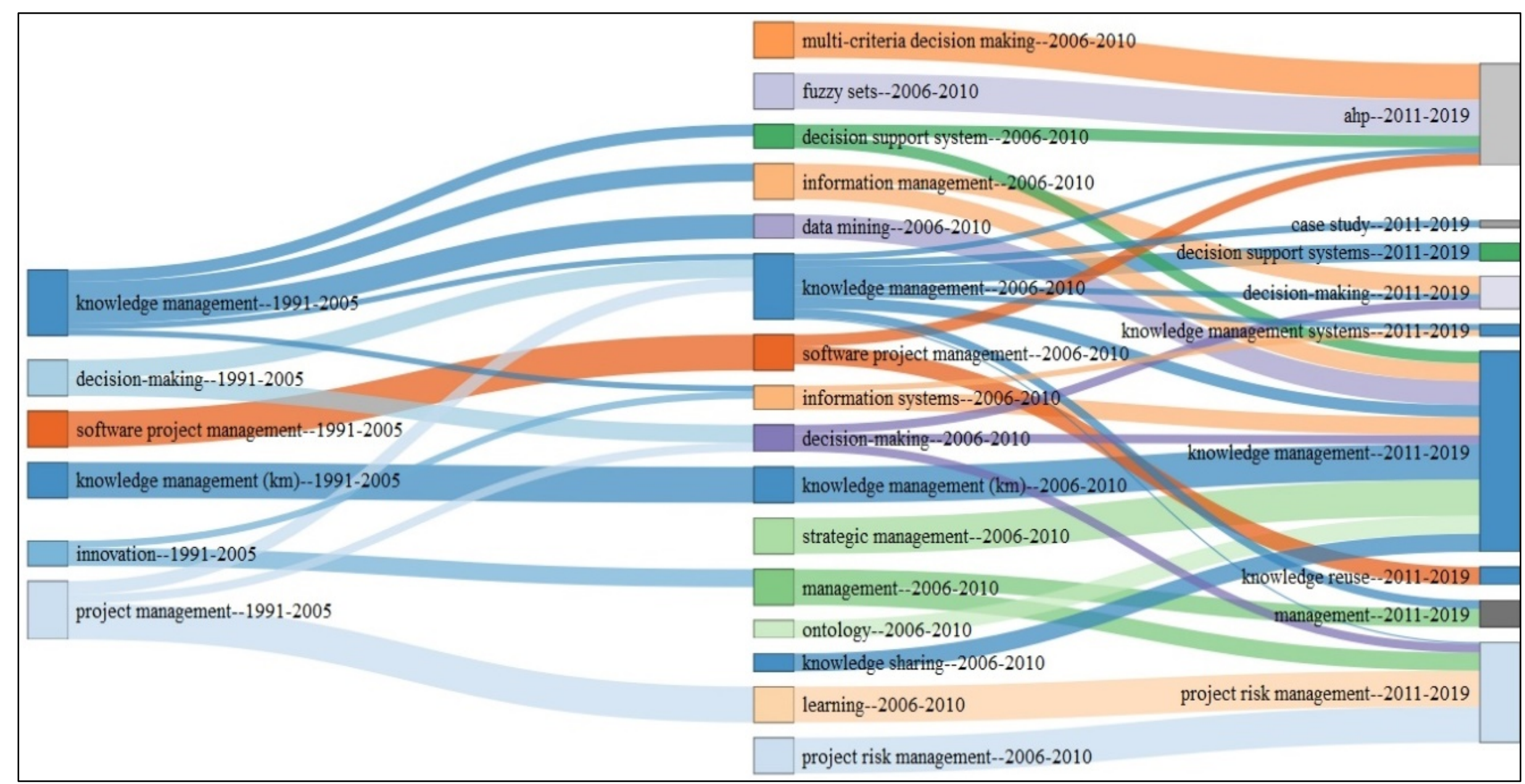

Figura 8: Evolução temática da amostra analisada Fonte: elaborado pelos autores. 
A Figura 8 mostra que inicialmente que as palavras-chave estudadas circunscreviam um campo ainda limitado, que ao longo do tempo suscitou novas pesquisas envolvendo métodos de tomada de decisão. $\mathrm{O}$ surgimento de case study como palavra-chave mostra que os trabalhos com base empírica começam a tornarse importantes a partir de 2011.

Há de se ressaltar o trabalho de Cagliano et al. (2015), que se destaca como um dos mais citados entre a amostra que considera as três palavras chave pesquisadas, sendo ainda o único que retornou quando substituiu-se o termo "project management" por "risk management", o que indica sua relevância. Para estes autores, o conhecimento sobre gerenciamento de riscos está se tornando uma questão de suma importância para lidar efetivamente com a complexidade dos projetos. Portanto, se faz necessário fornecer diretrizes para a seleção de técnicas de risco que leve em consideração os aspectos mais relevantes que caracterizam o cenário gerencial e operacional de um projeto. Nesse sentido, propõe-se um referencial teórico para classificar essas técnicas, no qual o gerenciamento do conhecimento assume papel protagonista como um elemento essencial.

A análise dos resultados obtidos sugere que o modelo teórico proposto contribui para as pesquisas destinadas a verificar como o gerenciamento do conhecimento e o gerenciamento de riscos em projetos pode influenciar a tomada de decisão dos profissionais nas organizações. Tal afirmação baseia-se no fato de que estas relações constituem um tema emergente, inseridos em uma área que vem evoluindo desde os anos 1990, além de cada vez mais envolver novos campos de pesquisa, mas que somente mais recentemente vem sendo estudada de forma mais direta, com a aplicação de estudos de caso e a formulação de trabalhos que propõem sua estruturação teórica de forma mais robusta.

\section{CONCLUSÃO}

O desenvolvimento de um modelo conceitual para avaliar as relações entre gestão do conhecimento e a tomada de decisões em projetos leva a necessidade de compreender os riscos envolvidos nos projetos. Tendo a incerteza como elemento sempre presente e bastante estudado nas teorias de projetos, a presente pesquisa explorou a necessidade do desenvolvimento de um novo construto, o qual versa sobre a gestão do conhecimento sobre riscos em projetos.

Para poder compreender este conceito foi necessário entender a estrutura do processo decisório em projetos, que pressupõe a coleta de dados, identificação e seleção de alternativas. O processo decisório acaba se aproximando da essência da gestão de riscos em projetos, por lidar com planejamento, identificação, qualificação, quantificação e controle das variáveis envolvidas.

De maneira similar, a gestão do conhecimento se apoia em uma estrutura básica, calcada na criação, captura, disseminação e aplicação de informações e conhecimentos. Nas pesquisas analisadas para a elaboração deste trabalho, verificou-se a combinação desses elementos citados anteriormente, que nesta proposta foram agrupados sob a temática de Gestão de Conhecimento sobre Riscos em Projetos. O delineamento de tal conceito permite compreender as necessidades de decisões estruturadas, caracterizadas pelos elementos teóricos básicos inerentes, que são os cenários, as alternativas e as consequências, bem como as regras para tomada de decisões em gestão de projetos.

Assim sendo, as principais variáveis e respectivos componentes da temática pesquisada, quais sejam: a) gestão de riscos em projetos; b) gestão de conhecimentos em projetos; c) processo decisório; d) estrutura de decisão e, por fim, e) eficácia da decisão - foram agrupados visando proporcionar assim uma visão mais abrangente das inter-relações existentes entre os temas até então independentes entre si em estudos anteriores considerados nesta pesquisa.

O modelo proposto é uma resposta à questão de pesquisa proposta e foi desenvolvido por meio de uma revisão sistemática da literatura desenvolvida em duas etapas, sendo a primeira exploratório e conceitual e uma segunda etapa de caráter confirmatório e quantitativo. Os resultados mostraram as relações entre os processos de gerenciamento de riscos em projetos, gerenciamento do conhecimento e tomada de decisão, descritos pelo modelo proposto. 
Apesar de o modelo ora delineado ter sua proposição fundamentada para utilização em estudos quantitativos, que frequentemente empregam perguntas do tipo "qual?", este pode ser utilizado para orientar pesquisas qualitativas, como os estudos de caso, nos quais as perguntas de pesquisa são do tipo "como?".

Finalmente, este trabalho contribui para a realização de novas pesquisas sobre gestão do conhecimento aplicada à gestão de projetos, combinado ao tema da teoria da decisão no contexto de riscos envolvidos em projetos. Ainda que limitado pela falta de dados empíricos, a presente contribuição fornece uma estrutura teórica para trabalhos deste tipo, concernentes à temática proposta. Pesquisas futuras poderão testar o modelo teórico proposto de modo a melhor compreender o comportamento de seus componentes em fenômenos empíricos.

\section{Referências}

Aria, M., \& Cuccurullo, C. (2017). Bibliometrix: An R-tool for comprehensive science mapping analysis. Journal of Informetrics, 11(4), 959-975.

Barney, J. (1991). Firm resources and sustained competitive advantage. Journal of management, 17(1), p. 99120.

Bernoulli, D. (1954). Specimen theoriae novae de mensura sortis, (Sommers, L., Trad.). Econometrica, 22, p. $23-$ 36.

Brereton, P., Kitchenham, B. A., Budgen, D., Turner, M., \& Khalil, M. (2007). Lessons from applying the systematic literature review process within the software engineering domain. Journal of systems and software, 80(4), 571-583.

Cagliano, A. C., Grimaldi, S., \& Rafele, C. (2015). Choosing project risk management techniques. A theoretical framework. Journal of Risk Research, 18(2), 232-248.

Carvalho, M. M.; Rabechini Junior, R. (2015). Impact of risk management on project performance: the importance of soft skills. International Journal of Production Research, 53(2), p. 321-340.

Centobelli, P., Cerchione, R., Esposito, E. (2017). Efficiency and effectiveness of knowledge management systems in SMEs. Production Planning \& Control, 30(9), p. 779-791.

Ceptureanu, S. I., Ceptureanu, E. G., Olaru, M., Popescu, D. I. (2018). An exploratory study on knowledge management process barriers in the oil industry. Energies, 11(8), p. 1-15.

Conrow, E. H. (2003). Effective risk management: Some keys to success (2nd. ed.). Reston, Virginia: American Institute of Aeronautics and Astronautics, Inc.

Cooper, D., Grey, S., Raymond, G., Walker, P. (2005). Project management guidelines: Managing risk in large projects and complex procurements. Chinchester, West Sussex, England: John Wiley \& Sons Itd.

Da Silva Nascimento, L., De Sousa Júnior, J. H. (2019). Relacionando capital intelectual, gestão do conhecimento e sustentabilidade: um modelo conceitual. Navus-Revista de Gestão e Tecnologia, 9(2), 92-104.

Dalkir, K. (2017). Knowledge management in theory and practice (3rd. ed.). Routledge.

Dean Jr., J.; Sharfman, M. (1993). Procedural rationality in the decision-making process. Journal of Management Studies, 30(4), p. 587-610.

Dean Jr., J.; Sharfman, M. (1996). Does decision process matter? A study of strategic decision-making effectiveness. Academy of Management Journal, 39(2), p. 368-392.

Eisenhardt, K. M. (1989). Making fast strategic decisions in high-velocity environments. Academy of Management Journal, 32(3), p. 543-576. 
Eisenhardt, K. M., Santos, F. M. (2006).Knowledge-based view of the firm: a new theory of strategy? In: Petigrew. A., Thomas, H.; Whittington, R. (eds.). Handbook of strategy and management. New York: Sage.

Fioravanti, V. S. L., \& Macau, F. R. (2017). Um modelo conceitual para o processo de transferência do conhecimento em cluster. Navus: Revista de Gestão e Tecnologia, 71), 111-134.

Ferraresi, A. A., Santos, S. A. dos. (2014). Os impactos da gestão do conhecimento na orientação estratégica, na inovatividade e nos resultados organizacionais: uma survey com empresas instaladas no Brasil. Revista de Administração Mackenzie, 15(2).

Gil, A. C. (2005). Métodos e técnicas de pesquisa social. São Paulo: Atlas.

Grant, R. M. (1996). Toward a knowledge-based theory of the firm. Strategic Management Journal, 17(2), p. 109-122.

Guillemette, M.; Laroche, M.; Cadieux, J. (2014). Defining decision making process performance: Conceptualization and validation of an index. Information \& Management, 51(6), p. 618-626.

Heath, C.; Tversky, A. (1991). Preference and belief: Ambiguity and competence in choice under uncertainty. Journal of Risk and Uncertainty, 4(1), p. 5-28.

Ibbs, C. W., \& Kwak, Y. H. (2000). Assessing Project management maturity. Project Management Journal, 31(1), 32-43.

Ilevbare, I. M.; Probert, D.; Phaal, R. (2014). Towards risk-aware roadmapping: Influencing factors and practical measures. Technovation, 34(8), p. 399-409.

Johansson, C.; Hicks, B.; Larsson, A.; Bertoni, M. (2011). Knowledge maturity as a means to support decision making during product-service systems development projects in the aerospace sector. Project Management Journal, 42(2), p. 32-50.

Kerzner, H. (2011). Gerenciamento de projetos - Uma abordagem sistêmica para planejamento, programação e controle (10a.ed., Gama Neto, J. \& Prado, J. Trads.) São Paulo, SP, Brasil: Edgard Blucher Ltda.

Keynes, J. M. (1921). A Treatise on Probability. Milton Keynes: Lightining Source.

Knigth, F. H. (1921). Risk, Uncertainty, and Profit. Boston: Hougthon Miffilin \& Co.

March, J. G. (1991). How decisions happen in organizations. Human-computer intere action, 6, p. 95-117.

Martins, G. A.; Theóphilo, C. R. (2010). Metodologia da Investigação Cientifica. São Paulo: Atlas.

Nonaka, I.; Takeuchi, H. (1997). Criação de conhecimento na empresa: como as empresas japonesas geram a dinâmica da inovação (2a ed.). Rio de Janeiro: Campus.

Nonaka, I.; Toyama, R. (2007). The knowledge-creating theory revisited: knowledge creation as a synthesizing process. Knowledge Management Research \& Practice, 1(1), p. 2-10.

Paré, G., Trudel, M. C., Jaana, M.,Kitsiou, S. (2015). Synthesizing information systems knowledge: A typology of literature reviews. Information \& Management, 52(2), 183-199.

Penrose, E. (1959). The theory of the growth of the firm. New York: Oxford University Press.

Peteraf, M. A. (1993). The cornerstones of competitive advantage: A resource-based view. Strategic Management Journal, 14(3), p. 179-191.

PMI. (2017). Um guia do conhecimento em gerenciamento de projetos - PMBOK GUIDE (6. ed.). Project Management Institute, Inc. Newton Square, PA. 
Rabechini Jr, R.; Carvalho, M. M. (2012). Relacionamento entre gerenciamento de risco e sucesso de projetos. Revista Produção, [online].

Rabechini Jr, R.; Carvalho, M. M. (2015). Understanding the impact of project risk management on project performance: an empirical study. Journal of Technology Management \& Innovation, 8, p. 6-6.

Radner, R. (1975). Satisficing. Journal of Mathematical Economics, 2, p. 253-262.

Raiffa, H. (1977). Teoria da decisão. São Paulo SP: Editora Vozes/USP.

Ramsey, F. P. (1931). Truth and probability. The foundations of mathematics and other logical essays. Eastford: Martin Fine Books.

Raz, T.; Michael, E. (2001). Use and benefits of tools for project risk management. International Journal of Project Management, 19(1), p. 9-17.

Raz, T., Shenhar, A., Dvir, D. (2002). Risk management, project success and technological uncertainty. $R \& D$ Management, 32(2).

Sampieri, R. H.; Collado, C. F.; Lucio, M. P. B. (2013). Metodologia de pesquisa. (5a. ed.). Porto Alegre: AMGH.

Savage, L. J. (1954). The foundations of statistics (3rd. ed.). New York: Dover Publications Inc.

Simon, H. (1955). A Behavioral Model of Rational Choice. The Quarterly Journal of Economics, 1(69), p. 99-118.

Simon, H. A. (1978). Rationality as process and as product of thought. The American economic review, 68(2), p. 1-16.

Wiig, K. (1993). Knowledge management foundations. Arlington, TX: Schema Press.

Wiig, K. M. (2003). A knowledge model for situation-handling. Journal of Knowledge Management, 75), p. 624.

Williams, T. (1995). A classified bibliography of recent research relating to project risk management. European Journal of Operational Research (85), p. 18-38.

Witte, E. (1972). Field research on complex decision making - the phase theorem. International Studies of Management \& Organization, 2(3), p. 156-182.

Zwikael, O.; Ahn, M. (2011). The effectiveness of risk management: an analysis of project risk planning across industries and countries. Risk analysis, 31(1), p. 25-37.

Zwikael, O.; Sadeh, A. (2007). Planning effort as an effective risk management tool. Journal of Operations Management, 25(4), p. 755-767. 